\title{
Magnet asymmetry in reduction of cogging torque for integer slot axial flux permanent magnet motors
}

\author{
Mehmet Gulec, Metin Aydin \\ Department of Mechatronics Engineering, Kocaeli University, Umuttepe Campus, Kocaeli 41380, Turkey \\ E-mail: metin.aydin@kocaeli.edu.tr
}

\begin{abstract}
Cogging torque component is one of the key issues in the design of radial and axial gap permanent magnet motors and the geometry and the position of the magnets plays a critical role in this process. This study presents the influence of magnet asymmetry in minimisation of the cogging torque for axial flux permanent magnet (AFPM) disc motors. Cogging torque minimisation techniques, such as magnet skewing and magnet shifting or groping are examined in detail by using threedimensional finite element analysis with various types of magnet skewing alternatives since the shaping and the positioning magnets are low cost approaches to minimise or eliminate the cogging component. A prototype AFPM disc motor is built with shifted magnets based on the models which are the results validated with the experimental results for the minimum cogging component and the sinusoidal back-EMF waveform. It is shown in this study that the cogging component in AFPM motors can be practically eliminated by using magnet asymmetry and perfectly sinusoidal back-EMF can also be obtained even for integer slot/pole/phase motors.
\end{abstract}

\section{Introduction}

Permanent magnet (PM) motors are being frequently used in numerous applications today because of their high efficiency, high torque density, small size and reliability $[1,2]$. Although magnet cost is always a major drawback as opposed to conventional AC and DC motors, the system cost including motor and drive is comparable in many applications.

Axial flux PM (AFPM) motors are usually recognised as an alternative to conventional PM motors because of their high torque density, efficiency and geometric advantages. Structural advantages, suitability of high pole number applications and extremely low inertia for some AFPM topologies attract more attention by the researchers [3-9].

One of the critical design issues in both radial and axial flux PM motors are the torque pulsations and the torque quality. If preventive measures are not taken during the design process, torque pulsations may lead to noise, vibrations and mechanical and drive system related problems. In addition, it affects the motor performance especially at very low speeds.

In general, the torque output of a PM motor has four major torque components: average torque, torque ripple, reluctance torque and cogging torque. The reluctance torque component does not exist in surface magnet motors. Thus, minimisation of the torque ripple and the cogging torque components becomes extremely critical during the design stage. Torque ripple is caused by interaction between the winding MMF-harmonics and the slotted air gap of the motor. No-load torque that is also known as cogging torque is caused by interaction between the magnets and the stator slots. It is an undesirable component of the torque pulsations which generates problems at low speed control and position control applications. Various design related techniques are introduced in order to minimise or eliminate torque pulsations in radial gap PM motors [10-15]. Detailed analytical prediction and modelling of the cogging torque in radial gap PM motors [11], comparison of various design related techniques to lower or eliminate the cogging component again in radial gap PM motors [12, 13, 16] are well covered in the literature. Some of these techniques are skewing the magnets or slots, displacing and shaping the magnets, adding slots or teeth, optimising the magnet pole-arc-to-pole-pitch ratio, employing a fractional number of slots per pole, magnet/pole shifting and rotor displacement. Most of these methods can be applied to axial flux PM motors [17-20]. However, the topic of magnet or pole shifting is investigated for the RFPM motors [15, 16, 21-23] with less detail and has not been thoroughly investigated for the AFPM motors in the earlier studies.

Magnet skew, which is defined as creating an angle between the sides of the magnet and the stator slots, is one of the most effective techniques to reduce the cogging torque in AFPM motors. Various skewing methods are present and used in several types of axial gap PM motors. Cogging torque elimination in fractional slot axial gap PM motors is relatively easy and simple skewing techniques would be enough to eliminate the cogging to very low levels. In addition, the cogging torque component can be eliminated completely even in integer slot/pole/phase AFPM motors if skewing is calculated and used appropriately. In addition to magnet skew, magnet shifting or grouping, which is accomplished by moving the magnets of two adjacent poles with respect to each other, is also 
very effective in reducing the cogging torque. This approach was used in conventional radial gap PM motors in earlier studies. It was first presented in [15] and generalised in [12]. The first detailed paper about magnet shifting was presented in [23] with theory, numerical analysis and the test data of a 6 pole motor. However, magnet shifting approach has not been used in AFPM disc motors yet. By shifting or grouping the magnets in each AFPM rotor, asymmetric field distribution in each air gap is obtained to decrease the cogging torque component. When the magnet shifting method is adapted, new orders of cogging torque harmonics are introduced certainly in each of the air gaps. Therefore the magnet shifting could not work all the time for reducing the cogging torque in the AFPM motors. The analyses must be performed carefully to find the appropriate magnet combination and shifting angles.

The contribution of this paper is that this is the first detailed work focusing on the cogging torque minimisation of the AFPM motors with magnet shifting approach. The fact that the motor has an integer slot/pole/phase makes this paper more interesting. It is presented in this paper that it is possible to attain almost zero cogging and sinusoidal back-EMF for the slotted AFPM disc motors by simple magnet shifting on the rotor. To reach this goal, an AFPM motor with high cogging component is designed and built. Several magnet skewing and shifting approaches are used to lower the cogging torque component of the AFPM disc motor. Based on the finite element analysis (FEA) analyses and calculations, a prototype AFPM motor is built with shifted magnets to validate the designed rotor. Finally, the influences of magnet shifting on back-EMF and motor torque quality are also investigated and presented in this paper.

\section{Cogging torque principles}

Cogging torque is caused by the interaction between the magnets and the stator teeth or slot opening. In other words, it is caused by the variation of the magnetic energy of the field because of the magnets with the mechanical angular position of the rotor. However, the cogging torque fundamentally results from the non-uniform flux distribution in the air gap. As the teeth become saturated, the flux begins to distribute more evenly in the air gap and the cogging torque decreases. The cogging torque as
Table 1 Parameters of the reference axial flux PM motors

\begin{tabular}{lc}
\hline Number of poles & 8 \\
Number of stator slots & 24 \\
Air-gap length & $0.8 \mathrm{~mm}$ \\
Slots/pole/phase & 1 \\
Diameter ratio (stator ID/stator OD) & 0.56 \\
Magnet type & NdFeB $-\mathrm{N} 35 \mathrm{UH}$ \\
Lamination material & $\mathrm{M} 270-35 \mathrm{~A}$ \\
Number of turns per pole per phase & 9 \\
Winding & Star connected \\
\hline
\end{tabular}

a function of reluctance variation is described by

$$
T_{\operatorname{cog}}\left(\theta_{\mathrm{r}}\right)=-\frac{1}{2} \phi_{\mathrm{g}}^{2} \frac{\mathrm{d} R}{\mathrm{~d} \theta_{\mathrm{r}}}
$$

where $\theta_{\mathrm{r}}$ is the rotor position, $R$ is the air gap reluctance and $\phi_{\mathrm{g}}$ is the air gap flux. If the magnet strength is increased, the cogging torque also increases because of the increased amount of flux in the air gap. There are some studies modelling the reluctance variation in the RFPM motors [11]. However, no analytical model for cogging torque calculation exists in the AFPM disc motors. Therefore the cogging torque in the AFPM motors can be calculated more accurately and easily by means of numerical methods such as three-dimensional (3D)-FEA.

\section{Axial flux PM motor with fan shaped magnet}

In this paper, all the analyses are performed with double-rotor single-stator disc motor, which has a 24 -slot stator between two 8-pole rotor discs. The motor is designed with an integer slot/pole/phase so as to obtain a high cogging torque component. The stator is composed of a radially laminated core (also called tape wound core) and a lap type winding, whereas the rotor includes a mild-steel disc and standard fan-shaped surface mounted magnets. The motor parameters are given in Table 1.

The reference rotor with standard fan-shaped magnets is used as a benchmark structure. Fan-shaped magnet geometry with critical angles is displayed in Fig. $1 a$. The ratio of the magnet pole arc $\left(\alpha_{\mathrm{M}}\right)$, which is also called magnet pitch, to pole pitch $\left(\alpha_{\mathrm{P}}\right)$ is called magnet pole-arc
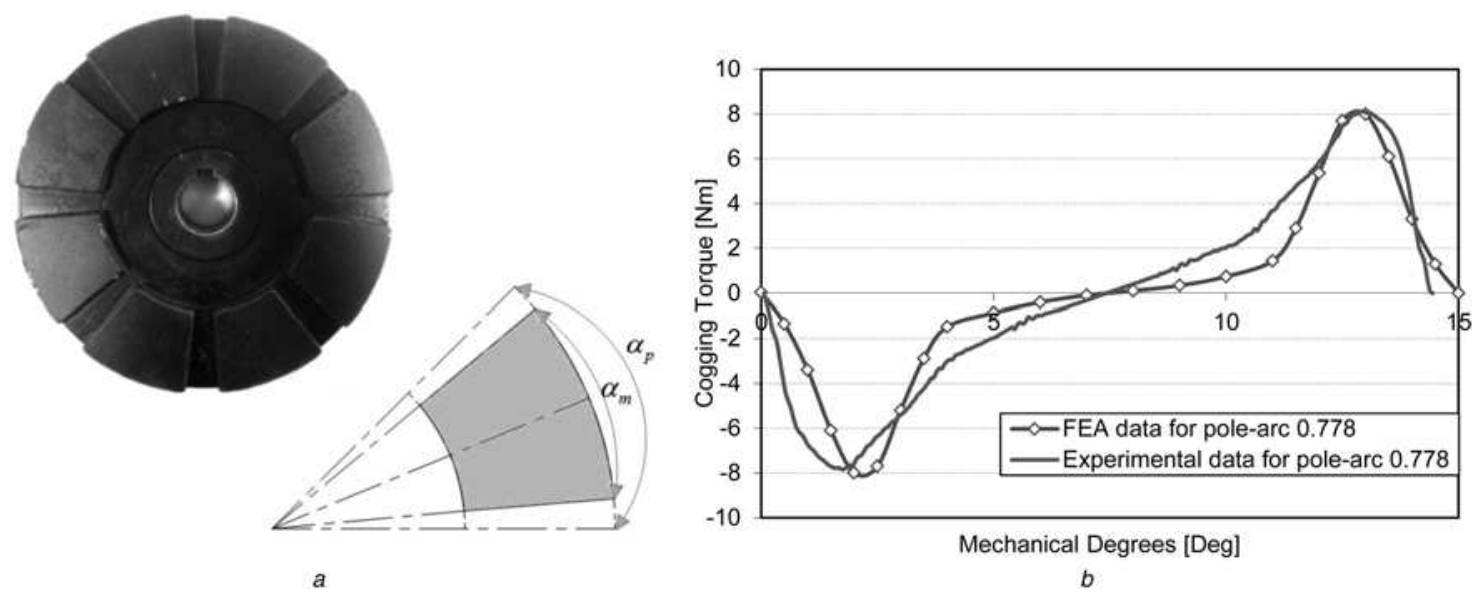

Fig. 1 Reference AFPM rotor details:

$a$ Built rotor structure with fan-shaped magnets and magnet geometry with critical angles

$b$ FEA predicted cogging torque waveform of the reference motor compared with the experimental results 
ratio and given by

$$
\alpha=\frac{\alpha_{\mathrm{M}}}{\alpha_{\mathrm{P}}}
$$

This ratio is selected as 0.778 for the reference AFPM motor during the design stage. In this paper, the magnet pole-arc ratio is investigated from 0.44 to 0.88 by using FEA and an optimum ratio is selected and compared with the experimental results.

The reference AFPM motor with a fan-shaped magnet has a peak cogging torque of $8 \mathrm{Nm}$ and the cogging torque waveform has $15^{\circ}$ of periodicity as expected. A good agreement between the FEA simulations and the experimental results in terms of the shape, magnitude and periodicity are observed for the reference motor structure and provided in Fig. $1 b$. This initial test result for the rotor with fan-shaped magnets in fact proves that the FEA works well for such analyses of the AFPM motors.

\section{Effect of the magnet skew in the cogging torque reduction}

Skewing magnet is a simple and useful cogging torque minimisation method used in both radial and axial field PM motors. In practice, this technique is generally applied by segmenting the rotors for standard radial gap PM motors, which generates manufacturing difficulties and cost. However, it can be performed easily in the AFPM motors because of their flat magnet surface and simple magnet geometry. Magnet skew in the AFPM motors can be accomplished by a few different means such as conventional skew, triangular skew, parallel-sided skew, trapezoidal skew, circular skew and dual-magnet skew [20].

In this paper, conventional magnet skew is investigated in detail. The geometry of the conventionally skewed magnet and the complete rotor structure are both shown in Fig. $2 a$. The conventional skew angle, $\beta$, is defined as the angle between the sides of the skewed and the fan-shaped magnets. It has to be indicated that $\beta$ is equal to zero for the reference fan-shaped magnet structure.

Variation of the peak cogging torque in two different magnet pole-arc ratios with conventionally skewed magnet is shown in Fig. $2 b$. It can be seen that the conventional skew is very effective in reducing the cogging torque. The reference AFPM motor, which has a 0.778 magnet-pole arc ratio, has an $8 \mathrm{Nm}$ peak cogging torque without any skewing. 20 mechanical degrees of conventional skew are applied to the fan-shaped magnets and the peak cogging torque is reduced by $80 \%$ with respect to the reference motor. Moreover, for the pole-arc of $0.667,88 \%$ of the peak cogging reduction is formed with $20^{\circ}$ of conventional skew.

A series of cogging torque simulations using 3D-FEA are completed for different magnet pole-arc ratios, and the variation of the peak cogging torque for both the un-skewed and the $20^{\circ}$ of conventionally skewed magnets are illustrated in Fig. 3. It is seen that the reference motor has an $8 \mathrm{Nm}$ peak cogging torque value with $\beta=0$ and the lowest peak cogging torque value appears at the 0.667 magnet pole-arc ratio. After applying $20^{\circ}$ of the conventional skew, the peak cogging torque is decreased considerably for all the magnet pole-arc ratios. Fig. $3 b$ shows a $2 \mathrm{D}$ view of the peak cogging torque variation for different magnet pole-arc ratios and conventional skew angles.

By using this plot obtained from many 3D-FEA simulations, the optimum conventional magnet skew angle and the magnet pole-arc ratios as well as the cogging trend can be found for this AFPM motor structure. All the magnet pole-arc ratios have the lowest cogging torque at 20.0 mechanical degrees of the conventional skew and it can be seen in the figure that the motor, which has a 0.667 magnet pole ratio, has the lowest cogging torque with the un-skewed and the conventional skewed magnets. However, the drawback of such a design point is the non-sinusoidal back-EMF waveform.

It needs to be mentioned that the skew angle $\beta$ does not have to be the same on both sides of the magnet. However, if different skew angles are used on both sides, the number simulations increase considerably. Furthermore, motor manufacturing would create additional problems because of the asymmetrical magnet shapes.

\section{Analysis of the asymmetric magnets in the AFPM motors}

In the conventional AFPM motors with the integer slot/pole/ phase, the cogging torque contributions from each magnet are all in phase, which results in the full cogging torque profile of
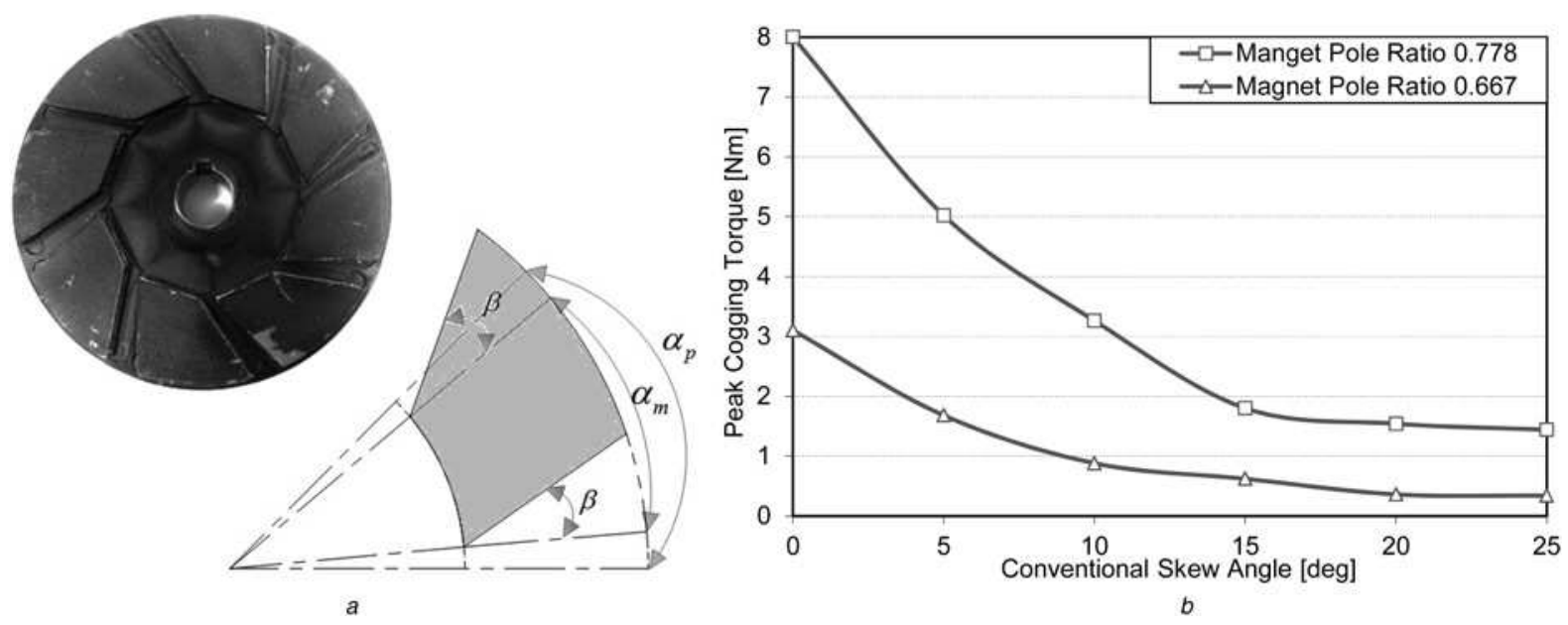

Fig. 2 Skewed AFPM rotor details:

$a$ Built rotor structure with skewed magnets and magnet geometry with the critical angles

$b$ Variation of the peak cogging torque with conventional magnet skew for the magnet pole-arc ratios of 0.667 and 0.778 


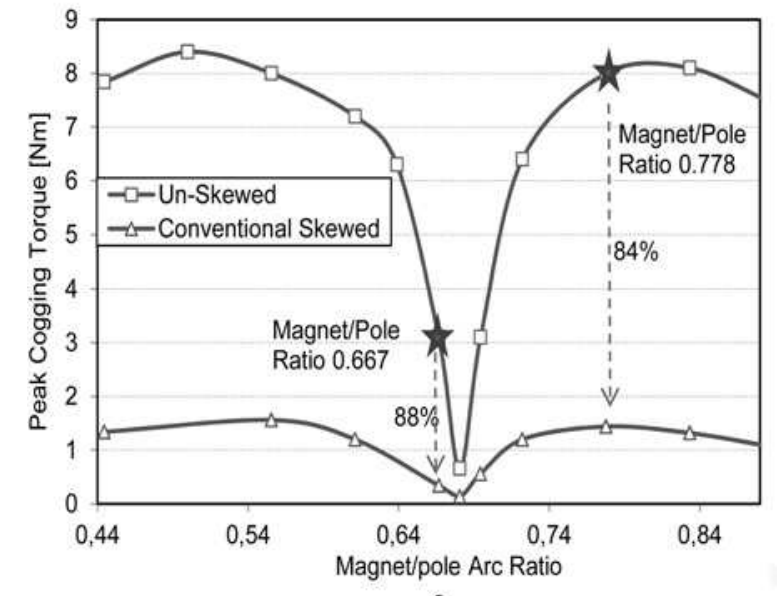

a

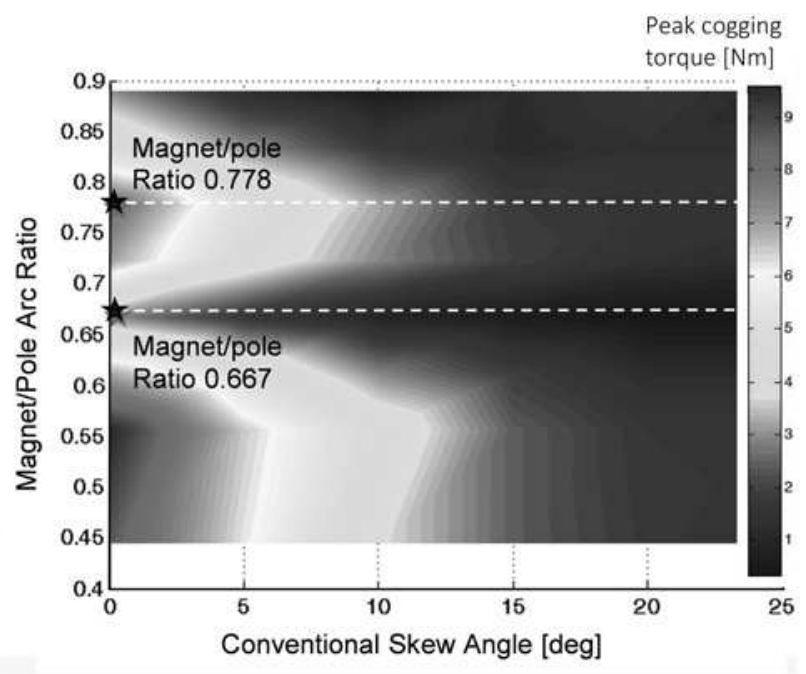

b

Fig. 3 Variation of the peak cogging torque as a function of

$a$ Magnet pole arc ratio

$b$ Conventional mechanical skew angles and magnet pole-arc ratios

the motor. To avoid this, the magnets can be shifted or grouped relative to each other in each rotor, so that each magnet's cogging torque contribution can be out of phase with the others and the net cogging effect can be reduced [12]. In other words, the magnets are grouped or shifted so that the shifted cogging torque contributions of each magnet result in a reduced cogging waveform. For an 8-pole disc motor, two options of the shifting magnets are provided in Fig. 4. As the pole number increases, more grouping options can be arranged. However, it should be mentioned that as the magnets are shifted from their symmetrical positions, the leakage flux increases on one side of magnet and decreases on the other side $[15,23]$.

Magnet shifting depends on whether or not the number of slots per pole is an integer. The AFPM motor used in this paper has an integer slot per pole per phase. Therefore each magnet pole sees a complete number of several stator teeth. Consequently, the cogging effects of each magnet become all in phase and are added to each other.

The contribution of the cogging torque for each magnet is given by

$$
T_{\operatorname{cog}}=\sum_{k=1}^{\infty} T_{p k} \sin \left(N_{\mathrm{s}} k \theta\right)
$$

where $T_{p k}$ is the Fourier coefficient of the cogging torque for each magnet and $N_{\mathrm{s}}$ is the number of stator slots. The total cogging torque waveform for $m_{1}$ number of rotors and $2 p$ number of poles is

$$
T_{\operatorname{cog}}=2 p m_{1} \sum_{k=1}^{\infty} T_{p k} \sin \left(N_{\mathrm{s}} k \theta\right)
$$

Each magnet in each rotor disc is in phase with the rest and hence generating a high cogging component. If the magnet shifting is considered, the total cogging torque of each rotor

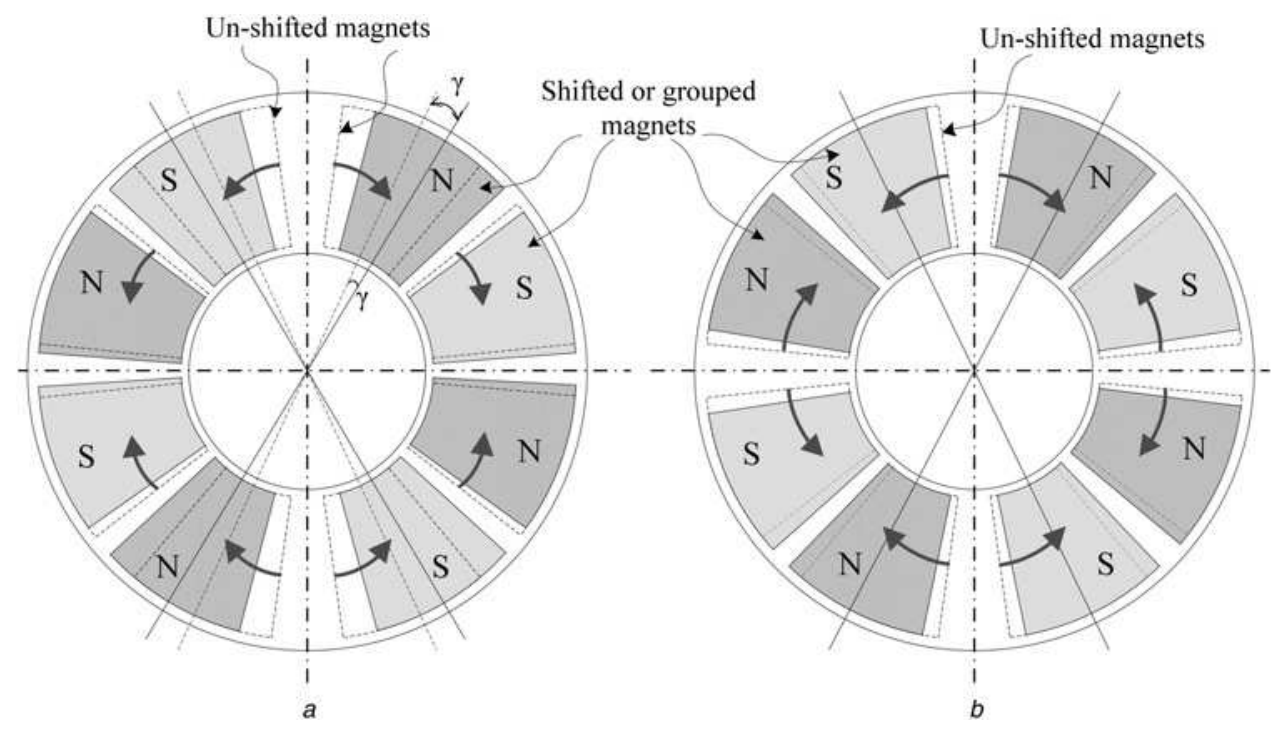

Fig. 4 Options showing the shifting magnets in the 8 pole AFPM disc motors

$a$ Shifted in 4 and

$b$ Shifted in 2 


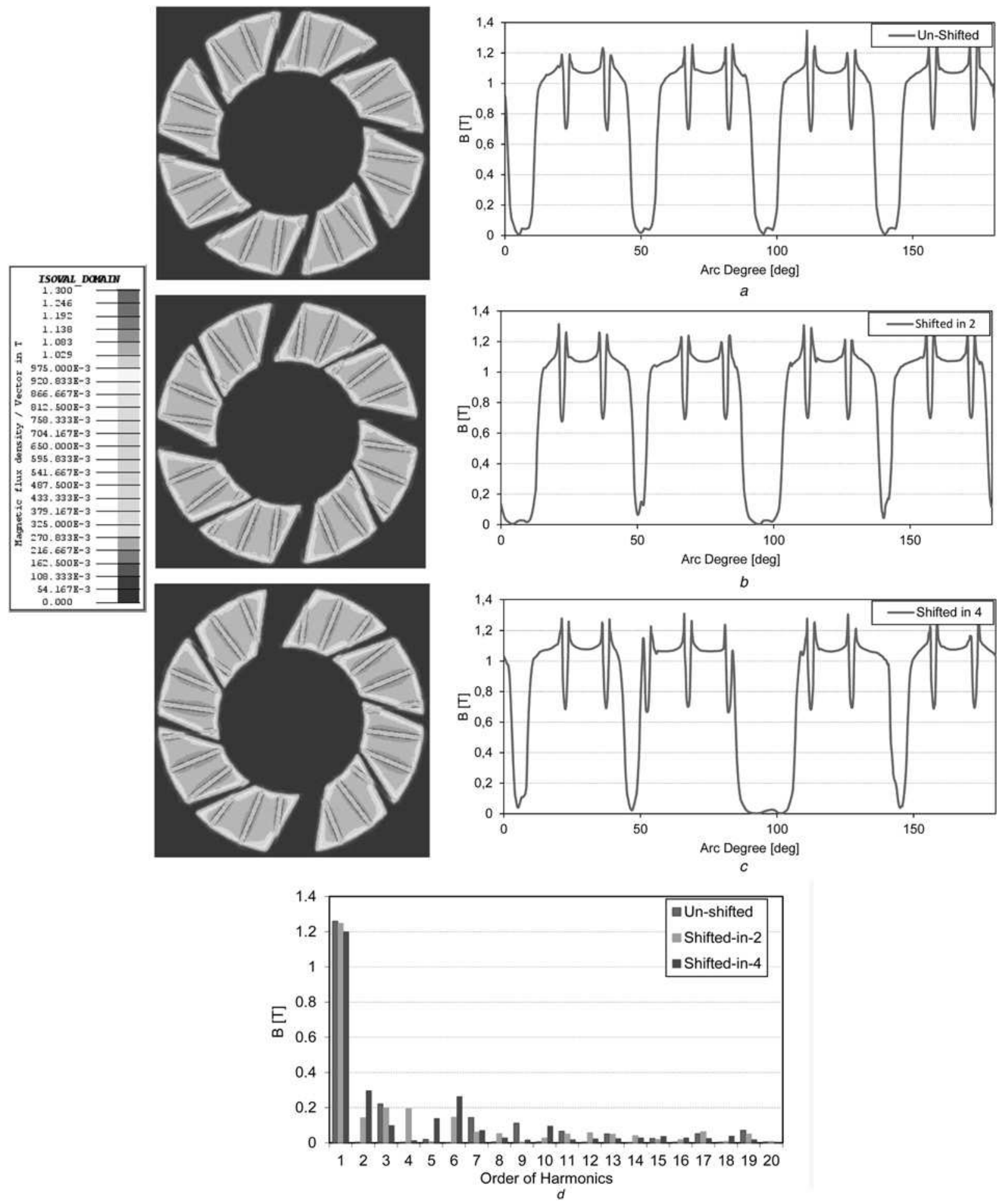

Fig. 5 No-load flux density distributions of

$a$ Un-shifted

$b$ Shifted-in-2

$c$ Shifted-in-4 for the conventional skew magnet type AFPM motor and the absolute value of the no-load flux density variation along 180 mechanical degrees in the middle of the air-gap and

$d$ FFT analysis of all the three cases

becomes the sum of the phase shifted contributions from each magnet and rotor, and is given by

$$
T_{\operatorname{cog}}=2 p m_{1} \sum_{h=0}^{2 p} \sum_{k=1}^{\infty} T_{p k} \sin \left(N_{\mathrm{s}} k(\theta-h \gamma)\right)
$$

where $\gamma$ is the shifting angle to cancel the cogging harmonics.
For the highest harmonic cancellation, $\gamma$ should be

$$
\gamma=180 \frac{k_{\mathrm{IO}}}{p N_{\mathrm{s}}}
$$

mechanical degrees where $k_{\mathrm{IO}}$ is a correction factor arising from the difference between the inner and the outer 
diameters of the disc motor. As an example, the AFPM motor used in this paper has 24 slots in the stator and 4 pole-pairs in each rotor. By assuming the same stator OD and ID, $\left(k_{\mathrm{IO}}=1\right)$, $1.875^{\circ}$ of mechanical shifting angle is expected by the formula. However, because of the difference in the stator $\mathrm{OD}$ and the ID in the disc motor, the shifting angle is expected to be slightly different. FEA of about $1.875^{\circ}$ showed that 2.0 mechanical degrees of shifting angle is sufficient to eliminate the highest cogging torque harmonics of the disc motor.

It has to be mentioned that the work in this paper is carried out for an 8-pole axial gap PM motor. As the pole number is increased in such motors, the torque quality can be improved easily even for the integer slot AFPM motors. As the pole number is lower than 8 such as 2 or 4 , reduction of cogging component could not be as easy as high pole motors although it can be reduced up to certain levels with magnet grouping.

\section{3D-FEA for the shifted magnets}

Numerical analyses are calculated by using 3D-FEA with Flux by Cedrat. First, a series of FEA simulations are carried out to illustrate the flux density levels of the shifted magnets for the double-rotor-single-stator AFPM motor. Fig. 5 shows the no-load air gap flux density distributions at the air gap and the FFT analysis for the cases of the conventional skew rotor and the magnets shifted-in-2 and shifted-in-4. It is seen that the un-shifted motor has more air-gap flux density levels than the shifted motors. Increased magnet leakage in the grouped structures is clearly seen from the picture.

Variations of the flux density in the air gap along the two pole-pairs are also provided in Fig. 5. Clearly, the un-shifted magnet case has lower field harmonic content than the shifted magnets as expected. The magnet shifting generates even harmonics because of the asymmetric field distribution and the THD level because the even harmonics become worse as the magnet shifting angle is increased. However, all these figures show that the rotor with the grouped or the shifted magnets results in more magnet flux leakage and higher field harmonic content as expected since the magnet symmetry is created in the air-gap flux density distribution. As the fundamental components of the fields are compared, the un-shifted geometry has the highest fundamental air-gap flux density component resulting in higher back-EMF and average torque component. The rotor with shifted-in-4 magnets has the worst harmonic content with even harmonics because of the magnet asymmetry. It has to be emphasised that while the THD of the un-shifted magnet case is $21.6 \%$, it becomes $27.6 \%$ for the shifted-in-2 magnet and $38.8 \%$ for the shifted-in- 4 magnet cases. As expected, the THD levels increase as more magnet asymmetry is generated.

However, the magnet grouping provides low levels of cogging since the contributions of the cogging torque from each magnet are out of phase. If the angles between the magnets are calculated correctly, the net cogging torque can be reduced to very low levels. It is obvious that as the magnets are shifted, the magnet leakage component increases, which results in decreased average flux density and obviously torque output, which will be investigated in the next section.

Figs. 6 and 7 show the cogging torque waveforms and the variations of the peak cogging as a function of the mechanical shifting angles for both the fan-shaped and the conventionally skewed magnets for the different magnet shifting cases using FEA. They show that the magnet shifting is indeed very effective in reducing the cogging components in the AFPM motors. As the fan-shaped standard rotor is considered and the rotor magnets are shifted in groups of 2 , minimum cogging is found at the shifting angle of $2.5^{\circ}$ (Fig. 7). This means that a $56.3 \%$ reduction in cogging can be attained with respect to the reference motor by shifting the magnets in groups of 2. If the rotor magnets are shifted in groups of 4, only 2.0 mechanical degrees of magnet shifting result in $87.5 \%$ cogging torque reduction with respect to the reference motor.

To see the influence of the magnet shifting for the conventional skew motor, a set of 3D-FEA analyses are also performed and the results are shown in Figs. 6 and 7. The conventional skew angle given in Fig. 2 is optimised and the minimum cogging torque value is found to be roughly $0.2 \mathrm{Nm}$. It has to be pointed out that the minimum cogging level is reduced from the 1.54 to the $0.68 \mathrm{Nm}$ peak for the rotor shifted-in-2 resulting in a $55.8 \%$ decrease in the cogging torque. When the same analyses are repeated for the magnets shifted-in- 4 , a $0.2 \mathrm{Nm}$ peak cogging is obtained at $\gamma=2^{\circ}$ resulting in a $87.5 \%$ decrease in the cogging component. As these levels are compared with the cogging level of $8 \mathrm{Nm}$ of the reference motor, it can be concluded that the rotor with the skewed magnets and the grouped-in-4 basically results in no cogging since a $97.5 \%$
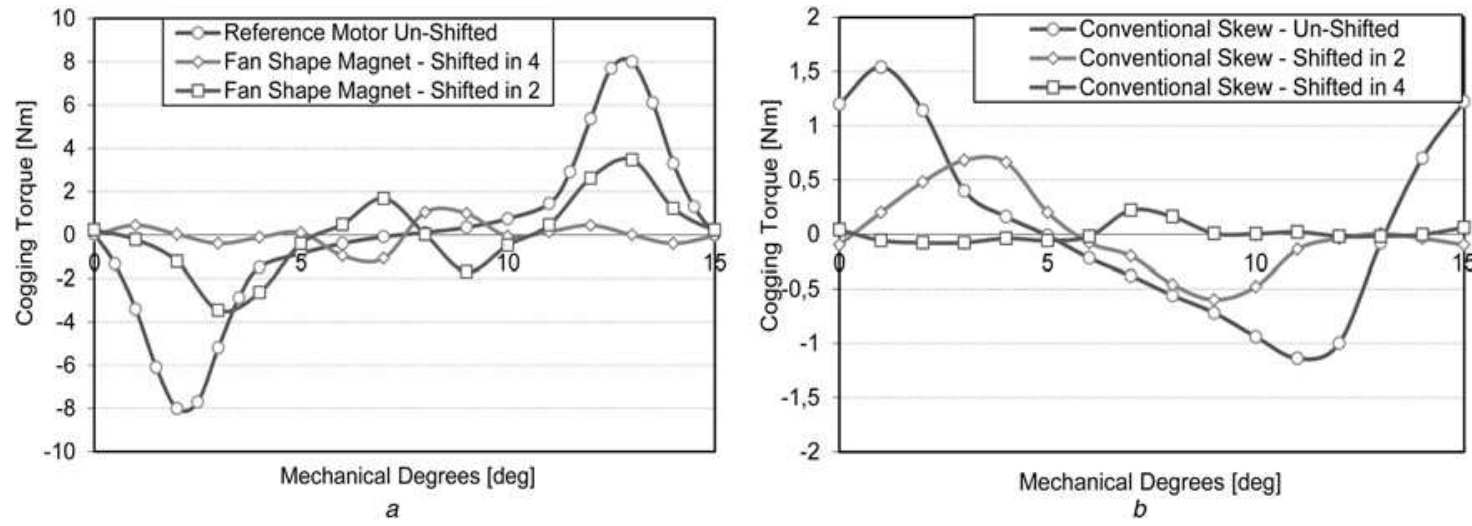

Fig. 6 Cogging torque waveform of the un-shifted, the shifted in 2 and 4 magnets for

$a$ Un-skewed and

$b$ Conventional skew magnets AFPM motors 

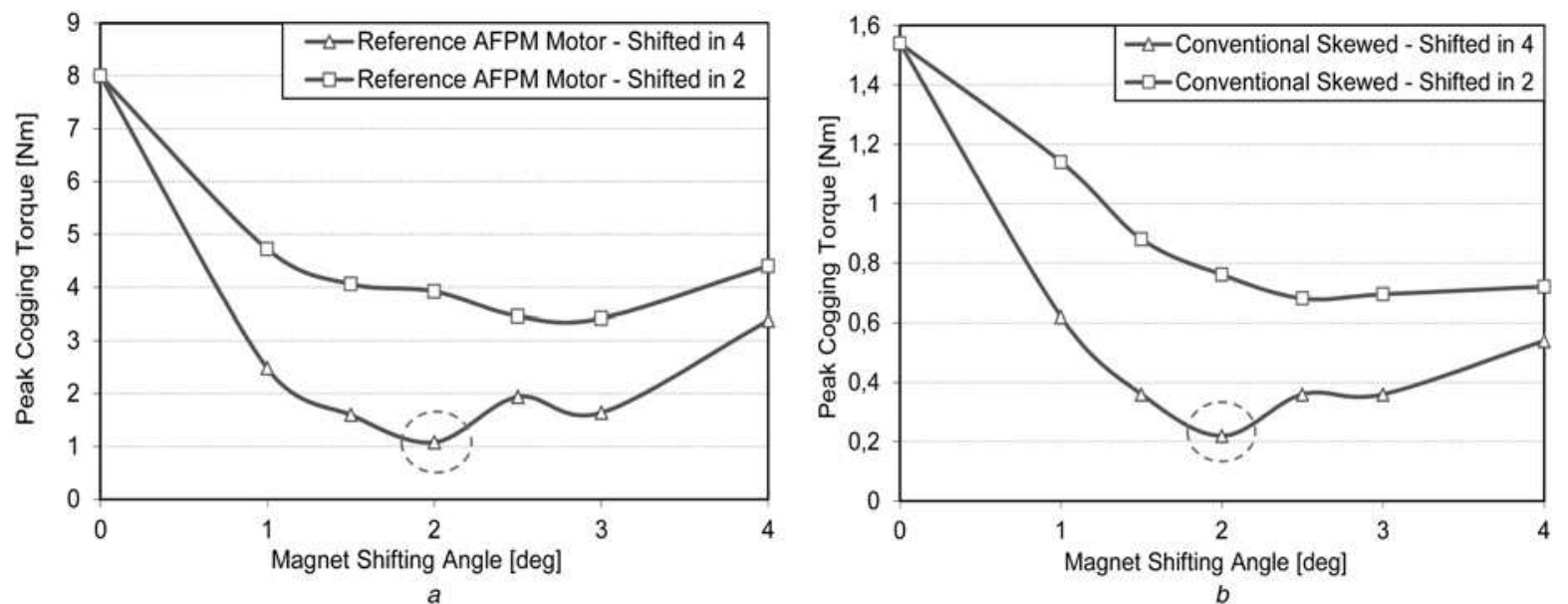

Fig. 7 Variation of the peak cogging torque of

$a$ Reference and

$b$ Conventional axial flux PM motor for the shifted in 2 and 4

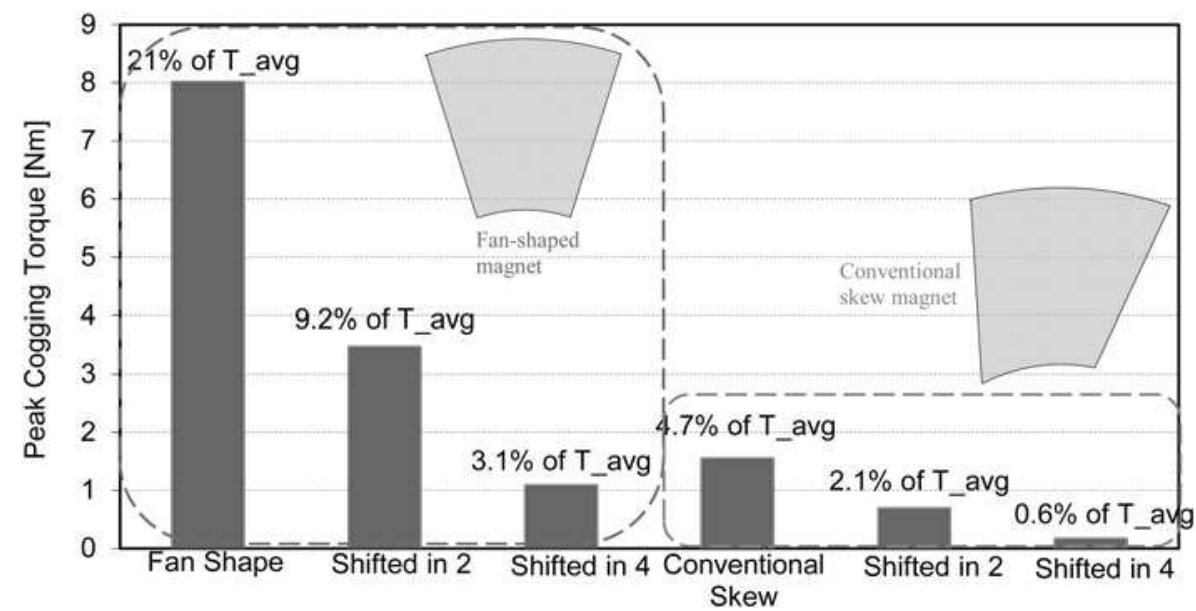

Fig. 8 Comparison of the peak cogging torque among the reference fan-shaped rotor, the triangular skewed rotor, the conventional skewed rotor and the rotor with shifted in 2 and shifted in 4

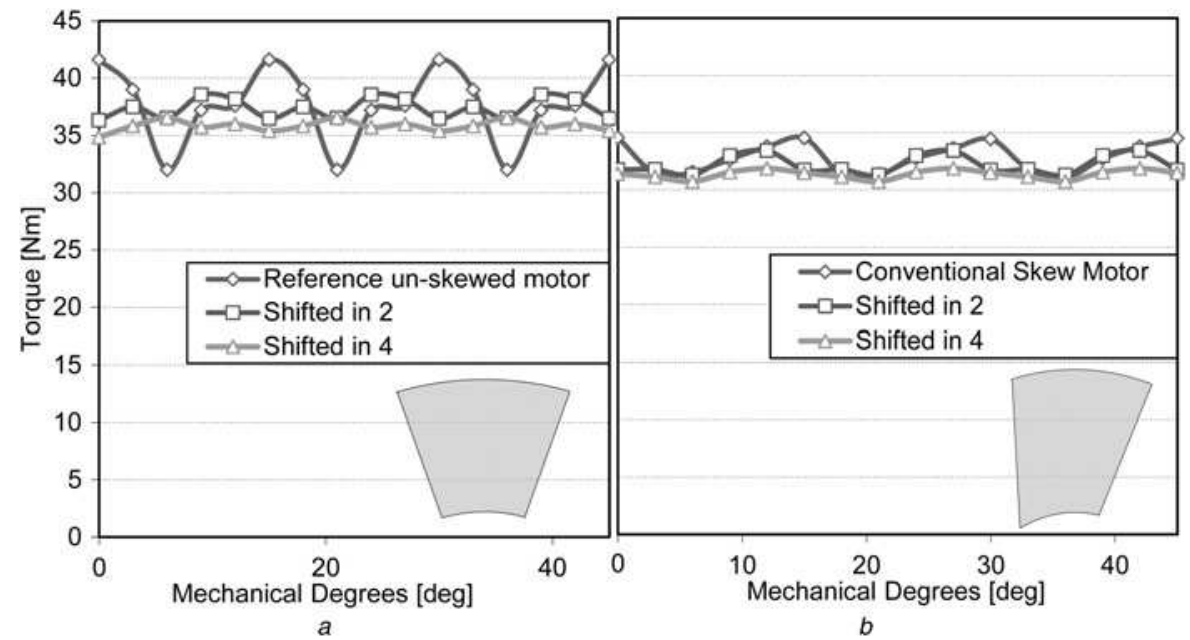

Fig. 9 Variation of the torque output for

$a$ Reference and

$b$ Conventional skew motors with shifted in 2 and 4 
Table 2 Comparison of the analysed rotors with the shifted magnets

\begin{tabular}{cccc}
\hline & $\begin{array}{c}\text { Average } \\
\text { torque, Nm }\end{array}$ & $\begin{array}{c}\text { Cogging } \\
\text { torque, \% }\end{array}$ & $\begin{array}{c}\text { Torque } \\
\text { ripple, \% }\end{array}$ \\
\hline reference motor & 37.7 & $21.1^{\mathrm{a}}$ & 25.4 \\
shifted in 2 & 37.4 & 9.2 & 6.0 \\
shifted in 4 & 35.8 & 3.1 & 4.7 \\
conventional skew & 32.9 & $4.7^{\mathrm{a}}$ & 10.7 \\
shifted in 2 & 31.8 & 2.1 & 6.6 \\
shifted in 4 & 31.4 & $0.5^{\mathrm{a}}$ & 3.6 \\
\hline
\end{tabular}

${ }^{\mathrm{a}}$ Experimentally verified data.

reduction can be confirmed. In other words, the magnet shifted-in-4 is more effective in reducing the cogging torque component as opposed to the magnets shifted-in- 2 .

Fig. 8 shows the comparison of the peak cogging torque of the fan-shaped and the conventionally skewed rotors with the un-shifted magnets and the shifted-in- 2 and 4 magnets. The results are given as the cogging percentage of the average torque. It is clearly seen that the magnet shifting technique is effective for both the magnet geometries to lessen the cogging component and is easily applicable to the disc rotors.

The magnets shifted-in-4 with conventional skew rotor are very attractive in reducing the cogging torque to extremely low levels. Thus, this option is selected to proceed with building the prototype motor.

\section{Torque pulsations via the FEA and comparison}

The output torques of the disc motor using different rotor and magnet configurations are explored by using 3D-FEA and the influences of the skewing and the shifting on the average torque are investigated. The FEA results are provided in Fig. 9 and summarised in Table 2. The effect of the magnet skew, in general, is evidently observed from the average torque reduction for both the fan-shaped and the conventional skew magnets. As the magnets are shifted (or magnet asymmetry is generated), up to a $4.5 \%$ drop in the average torque for both the fan-shaped and the skewed structures is attained because of magnet leakage while significant reduction in torque ripple is achieved.

\section{Prototype motor and experimental verifications}

To verify the FEA accomplished for the shifted magnets, a set of rotor with shifted-in-4 magnets is built and assembled to the disc motor. The manufactured rotor as well as the complete rotor structure are illustrated in Figs. $10 a$ and $b$. A test set-up displayed in Fig. $10 c$ is devised to test specifically the cogging torque component of the disc motor. The system comprises of a drive motor, inverter, high resolution torque-meter and the test motor. No

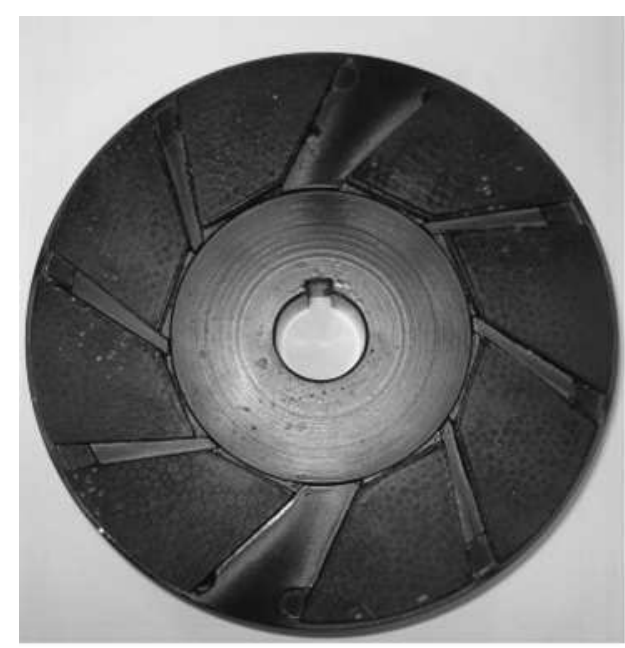

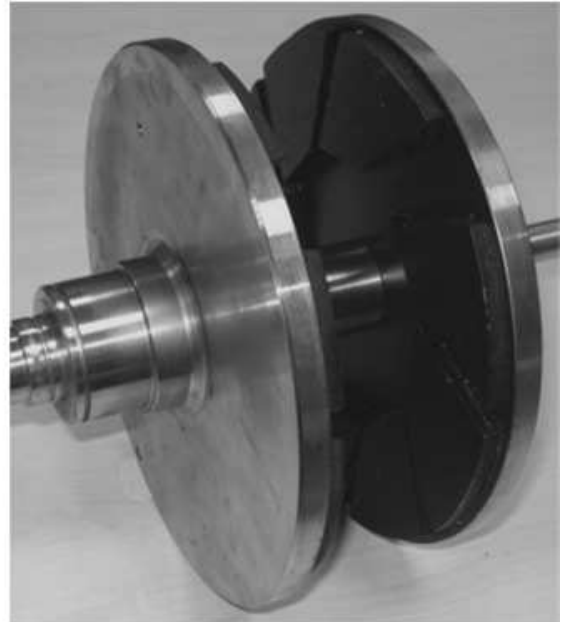

b

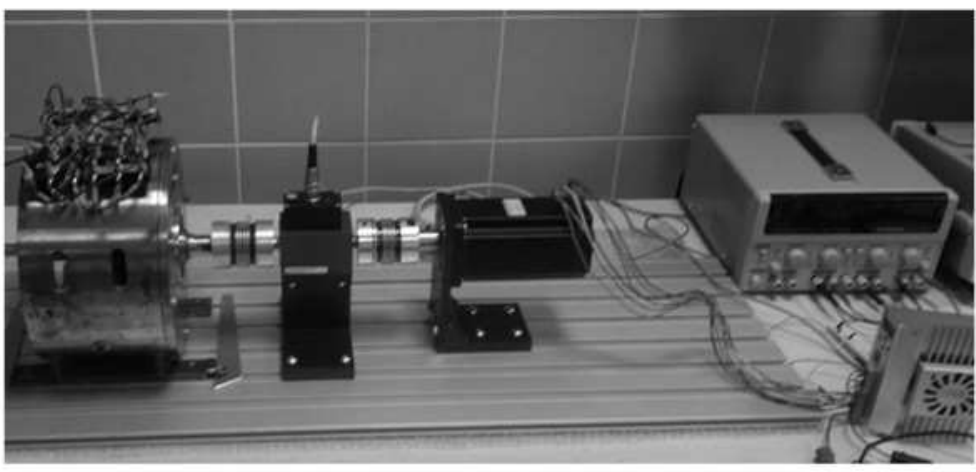

$c$

Fig. 10 Pictures of

$a$ Manufactured and tested disc rotor with the shifted-in-2 magnets

$b$ Complete rotor structure and

$c$ Test system to measure the cogging torque component of the disc motor 

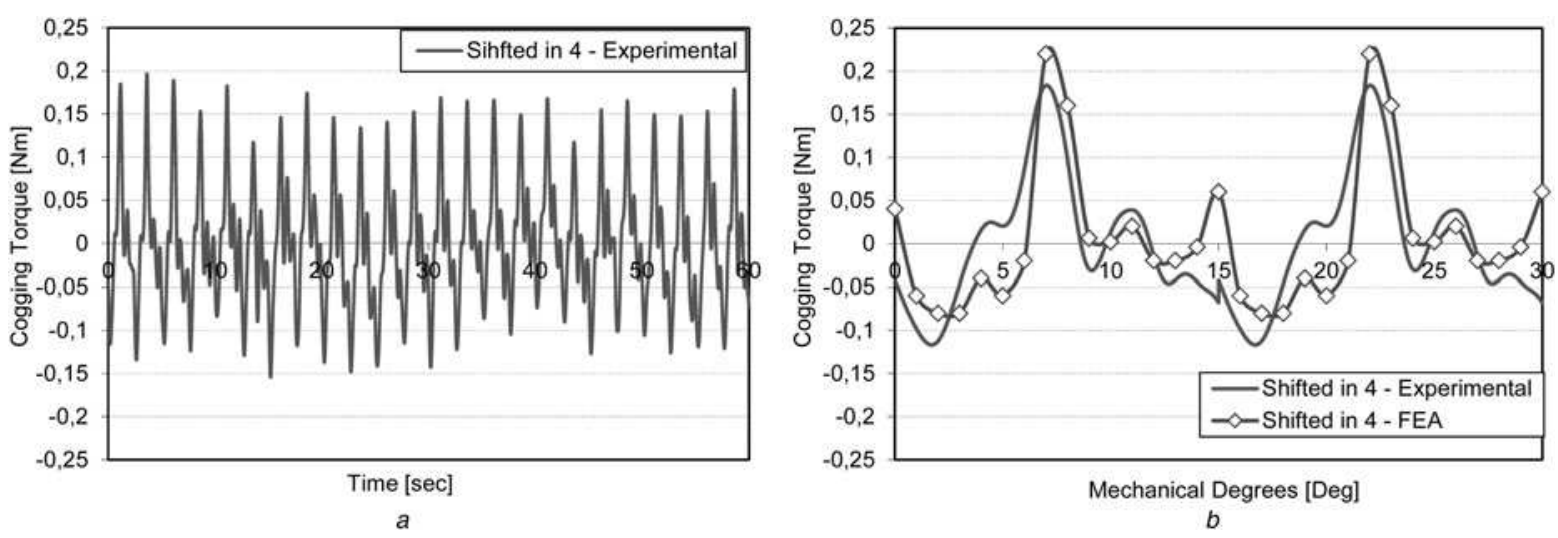

Fig. 11 Measurement of the cogging torque of the rotor with the skewed and the shifted magnets

$a$ Over $60 \mathrm{~s}$ and

$b$ Comparison of the 3D-FEA and the measured cogging torque over two cycles
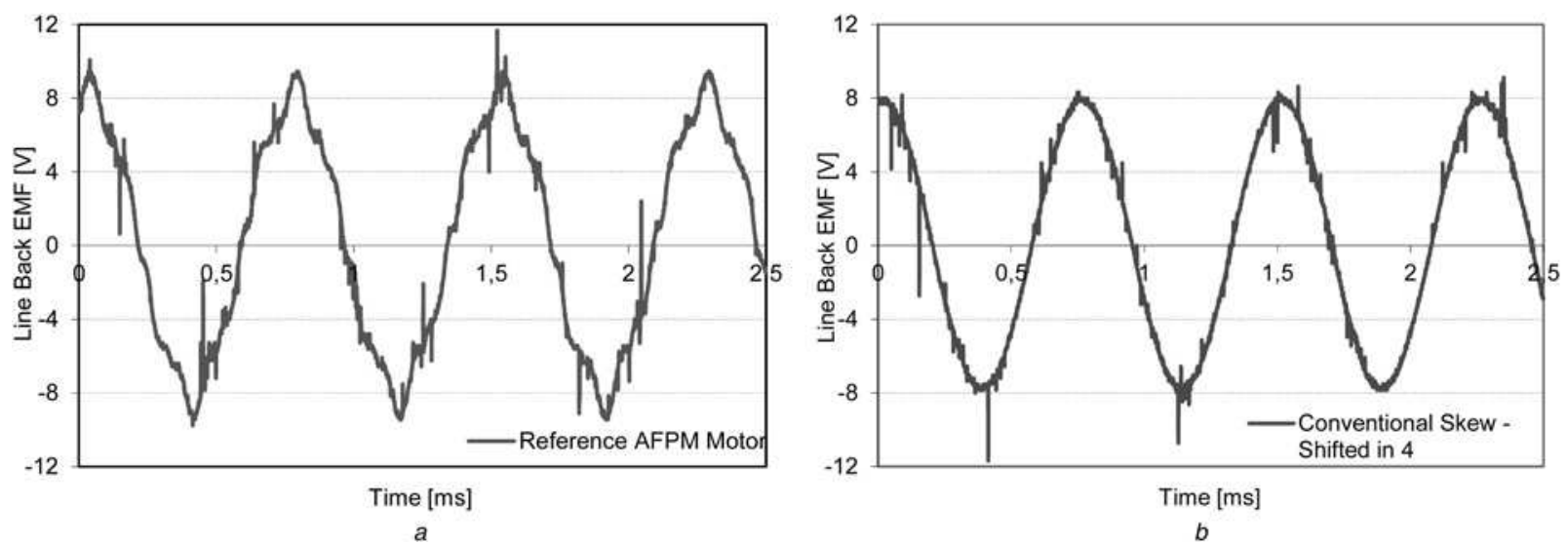

Fig. 12 Experimental back-EMF waveforms for

$a$ Fan-shaped reference motor and

$b$ Conventional skew motor with the shifted in four magnets

mechanical device is used in the system to eliminate the inaccuracies in measuring the cogging component.

It is imperative that the driving motor must have no cogging component whatsoever. Therefore a magnet-free step motor is used in the experimental system. The details of the driving motor are provided in the Appendix. The driving motor to test the cogging component is controlled at very low speeds so that accurate cogging information is attained. In addition, the driving motor must have no cogging or torque ripple whatsoever in order to obtain the correct cogging torque data of the tested AFPM disc motor.

Fig. 11a reports the measured cogging component of the shifted-in-4 rotor. The disc motor is rotated at $1 \mathrm{rpm}$ during the test so that one complete rotation is realised at $60 \mathrm{~s}$. The cogging torque data is obtained from a high-resolution torque-meter through a dSPACE 1104 system. Certainly, 24 cogging cycles with roughly $0.17 \mathrm{Nm}$ maximum cogging are observed during one rotation. Fig. $11 b$ shows the comparison between the 3D-FEA simulations and the experimental results of the shifted-in-4 rotor with skewed magnets. Good agreement between the simulated and the measured cogging data is noted in terms of the peak value and the shape with very small discrepancy.

Back-EMF waveforms of the reference motor and the built skewed rotor with shifted magnets are also obtained experimentally and shown in Fig. 12. Although the reference fan-shaped motor without any magnet shifting has 5th and 7th harmonics in the back-EMF waveforms, the skewed magnets with shifted-in-4 structure have perfectly sinusoidal back-EMF without any harmonics content.

\section{Conclusions}

Influences of the magnet shifting and the rotor asymmetry in minimisation of the cogging torque in a double-rotor AFPM motor have been studied in detail in this paper. A set 3D-FEA are carried out to attain the minimum cogging torque levels for the conventional skew magnets with and without the magnet shifting. The results are compared with the reference AFPM disc motor. The influence of the magnet shifting on the cogging and the torque output are laid out in detail by using 3D-FEA. A prototype rotor with skewed and shifted magnets has been built and the cogging torque is experimentally verified with the designed structure. It can be concluded that the magnet-shifting can easily be applied to most AFPM motors without complicating the production process. It is easy to implement in production without getting into complicated magnet geometries in the AFPM motors. In addition, the cogging component of the shifted magnet structure can be reduced to very low levels after careful calculations since it is 
a crucial issue for low speed applications with a penalty of some average torque reduction. It is also found that the magnet geometry is very sensitive in obtaining correct cogging data as well as shifted magnets and it is shown that it is possible to design a cogging free AFPM disc motor with perfectly sinusoidal back-EMF even with integer slot/ pole/phase motors. Finally, it is possible to obtain sinusoidal back-EMF and eliminate back-EMF harmonics if the shifting angle is properly applied.

\section{Acknowledgment}

The authors are indebted to ENPAY co. for providing strip cores of the motor prototype and Cedrat Co. for providing the Flux software.

\section{References}

1 Hendershot, J.R., Miller, T.J.: 'Design of brushless permanent magnet motors' (Clarendon, Oxford, UK, 1994)

2 Hanselman, D.: 'Brushless permanent magnet motor design' (Magna Physics Pub, USA, 2006)

3 Cavagnino, A., Lazzari, M., Profumo, F., Tenconi, A.: 'A comparison between the axial flux and the radial flux structures for PM synchronous motors', IEEE Trans. Ind. Appl., 2002, 38, (6), pp. $1517-1524$

4 Sitapati, K., Krishnan, R.M.: 'Performance comparisons of radial and axial field, permanent-magnet, brushless machines', IEEE Trans. Ind. Appl., 2001, 37, (3), pp. 1219-1226

5 Mahmoudi, A., Kahourzade, S., Rahim, N., Ping, H.W., Uddin, M.N. 'Design and prototyping of an optimised axial-flux permanent-magnet synchronous machine', IET Electr. Power Appl., 2013, 7, (5), pp. 338-349

6 Aydin, M., Huang, S., Lipo, T.A.: 'Torque quality and comparison of internal and external rotor axial flux surface-magnet disc machines', IEEE Trans. Ind. Electron., 2006, 53, (3), pp. 822-830

7 Aydin, M., Huang, S., Lipo, T.A.: 'Axial flux permanent magnet disc machines: a review'. SPEEDAM, Capri, Italy, 2004

8 Stefano, R.D., Marignetti, F.: 'Electromagnetic analysis of axial flux permanent magnet synchronous machines with fractional windings with experimental validation', IEEE Trans. Ind. Electron., 2012, 59, (6), pp. 2573-2582

9 Alberti, L., Fornasiero, E., Bianchi, N., Bolognani, S.: 'Rotor loses measurements in an axial flux permanent-magnet machine', IEEE Trans. Energy Convers., 2011, 26, (2), pp. 639-645

10 Jahns, T.M., Soong, W.L.: 'Pulsating torque minimisation techniques for permanent magnet ac motor drives: a review', IEEE Trans. Ind. Electron., 1996, 43, (2), pp. 321-330
11 Zhu, Z.Q., Howe, D.: 'Analytical prediction of the cogging torque in radial-field permanent magnet brushless motors', IEEE Trans. Magn., 1992, 28, (2), pp. 1080-1083

12 Bianchi, N., Bolognani, S.: 'Design techniques for reducing the cogging torque in surface-mounted PM motors', IEEE Trans. Ind. Appl., 2002, 38, (5), pp. 1259-1265

13 Bianchini, C., Immovilli, F., Bellini, A., Davoli, M.: 'Cogging torque reduction methods for internal permanent magnet motors: review and comparison'. Proc. XIX Int. Conf. on Electrical Machines, Marseille, France, 2010, pp. 1-6

14 Fei, W., Luk, P.C.K.: 'A new technique of cogging torque suppression in direct-drive permanent-magnet brushless machines', IEEE Trans. Ind. Appl., 2007, 46, (4), pp. 1332-1340

$15 \mathrm{Li}, \mathrm{T}$., Slemon, G.: 'Reduction of cogging torque in PM motors', IEEE Trans. Magn., 1988, 24, (6), pp. 2901-2903

16 Bianchi, N., Bolognani, S., Cappello, A.D.F.: 'Reduction of cogging force in PM linear motors by pole-shifting', IEEE Proc. Electr. Power Appl., 2005, 152, (3), pp. 703-709

17 Caricchi, F., Capponi, F.G., Crescimbini, F., Solero, L.: 'Experimental study on reducing cogging torque and core power loss in axial-flux permanent-magnet machines with slotted winding'. IEEE Industry Applications Society Annual Meeting, Pittsburgh, USA, 2002, pp. 1295-1302

18 Aydin, M., Qu, R., Lipo, T.A.: 'Cogging torque minimization technique for multiple-rotor, axial-flux, surface-mounted-PM machines: alternating magnet pole-arcs in facing rotors'. IEEE Industry Applications Society Annual Meeting, Utah, USA, 2003, pp. 555-561

19 Aydin, M., Zhu, Z.Q., Lipo, T.A., Howe, D.: 'Minimization of cogging torque in axial-flux permanent-magnet machines: design concepts', IEEE Trans. Magn., 2007, 43, (9), pp. 3614-3622

20 Yolacan, E., Ozyurt, E., Aydin, M.: 'Magnet shape optimization of a slotted surface-mounted axial gap PM motor for reducing cogging torque'. Int. Conf. on Electric Machines, Rome, Italy, 2010, pp. 1-6

21 Wang, D., Wang, X., Yang, Y., Zhang, R.: 'Optimization of magnetic pole shifting to reduce cogging torque in solid-rotor permanentmagnet synchronous motors', IEEE Trans. Magn., 2010, 46, (5), pp. $1228-1234$

22 Liu, T., Huang, S., Gao, J.: 'A method for reducing cogging torque by magnet shifting in permanent magnet machines', IEEE Trans. Ind. Appl., 2007, 43, pp. 1565-1571

23 Dosiek, L., Pillay, P.: 'Cogging torque reduction in permanent magnet machines', IEEE Trans. Ind. Appl., 2007, 43, (6), pp. 1565-1571

\section{Appendix}

Drive motor manufacturer and model: SOYO Co. Model no: SY85STH156.

Drive motor data: $T_{\text {hold }}=12.5 \mathrm{Nm}, I_{\text {phase }}=4.2 \mathrm{~A}, R_{\text {phase }}=$ $1.25 \Omega, L_{\text {phase }}=12 \mathrm{mH}$ and no rotor magnets. 